\title{
The Effect of CBLL on Improving Students' Dispositions towards Critical Thinking
}

\author{
Liya Liu \\ Huazhong Agricultural University, Hubei 430070, China \\ liuliya@mail.hzau.edu.cn,624652539@qq.com
}

\begin{abstract}
It is widely accepted that thinking is closely related to language and that the development of thinking can occur in the process of language learning. Therefore it becomes one of researchers' top concerns to cultivate a robust disposition towards critical thinking among students. This study aims to explore the impacts of CBLL (Content-based language learning) on EFL learners' dispositions towards critical thinking. There are two groups of participants in the current research: an experimental group of 38 students and a control group of 41 students. Both of the two groups are students from class A in which learners were enrolled with better English test records. They were then randomly divided into two groups. In the experimental group, English learning was instructed based on the principles of CBLL. While in the control group, English was taught to the subjects in the regular way. CTDI-CV (Critical Thinking Disposition Inventory-Chinese Version) was the instrument to measure the development of the subjects' disposition towards critical thinking. After one academic year, the researcher analyzed the collected data from the two rounds of questionnaires by independent samples t-test and paired samples t-test. It is revealed that EFL learners in the CBLL class perform positive development in their dispositions towards critical thinking. They show significant improvement in the aspects of dispositions as truth seeking, systematicity and overall tendency. The result signifies that CBLL can effectively help develop students' critical thinking disposition. The justifications for the result are discussed in the last parts of the paper.
\end{abstract}

Keywords: CBLL; Critical thinking disposition; Language learning.

\section{Introduction}

Human thinking and language are two interwoven process in mind developing. Language is the tool for thinking and thinking is the content for language output. The relationship between language and thinking has always been recognized by educators $[1,2]$. According to Renner, higher rank thinking ability can facilitate learners' higher learning ability therefore enhance language acquisition [3]. As to thinking ability, there has been an expert consensus regarding critical thinking and the ideal critical thinker. "The ideal critical thinker is habitually inquisitive, well-informed, trustful of reason, open-minded, flexible, fair-minded in evaluation, honest in facing personal biases, prudent in making judgments, willing to reconsider, clear about issues, orderly in complex matters, diligent in seeking relevant information, reasonable in the selection of criteria, focused in inquiry, and persistent in seeking results which are as precise as the subject and the circumstances of inquiry permit. Thus, educating good critical thinkers means working toward this ideal. It combines developing CT skills with nurturing those dispositions which consistently yield useful insights and which are the basis of a rational and democratic society" [4].

A large amount of research testifies that positive disposition towards critical thinking can be cultivated through education $[5,6]$. Unfortunately, in mainland China, there are many reports on no change or even negative tendency of CTD over college students' four year academic study [7-9]. Despite of the internal complex reasons for the changes, it's still meaningful and practical for educators to reflect on their teaching methods and make efforts to contribute developing students' CTD. Therefore, the researchers in present study conducted a teaching experiment among a group of college students and explored the impacts of the specific CBLL (Content-based language learning) on the development of EFL learners' dispositions towards critical thinking. 


\section{Literature Review}

\subsection{CBLL and the Theoretical Background}

CBLL (Content-based language learning) derives from the immersion class in Canada in the 1960s. It combines language study with subject study. One of the most popular models is theme-based model in which the contents of the course are organized around themes that form the basis for language analysis. Many second language acquisition theories prop up content based language learning. According to the input hypothesis [10] and interaction approach [11], language is acquired through a sufficient amount of comprehensible input and opportunities to interact with the language by producing and receiving feedback on it. In CBLL model, students are provided with substantial theme-based authentic language input both in and after classes.

\subsection{Researches on CTD and CBLL}

CTD (Critical thinking disposition), first proposed by American Delphi project, refers to natural tendencies, or personal inclinations to demonstrate critical thinking skills [4]. Facione et al. described seven traits or dispositions of critical thinkers, which included truth-seeking, open-mindedness, analyticity, systematicity, self-confidence, inquisitiveness and maturity [12].

According to Facione et al., "there is a growing consensus that a complete approach to developing college students into good critical thinkers must include the nurturing of the disposition toward critical thinking. Some might argue that cultivating the disposition is necessary before implanting the skills, but a developmental perspective would suggest that skills and dispositions are mutually reinforced and, hence, should be explicitly taught and modeled together. In either case, common sense tells us that a strong overall disposition toward critical thinking is integral to insuring the use of critical thinking skills outside the narrow instructional setting."[12] Thus it is necessary for language teachers to include nurturing students' critical thinking disposition into their teaching plans.

Researches abroad have alreadyproved the promoting effect of higher education on CTD $[5,6,13$, 14]. However, empirical studies in mainland China found that there was no increasing tendency of CTD over college education [7,8].Given the disappointing results, the researchers in this study determined to organize their learning plans based on the principle of CBLL. In dealing with various logically related authentic materials students are obliged to stimulate various critical thinking skills including interpreting, analysizing, inferring, evaluating etc. As a result, personal ideas can formed and finally acquired critical thinking skills. This content-based instruction put equally important emphasis on both content and language learning, therefore can facilitate content learning and promote critical thinking skills and language proficiency as well [15]. The present research is designed to test whether CBLL adopted in the teaching experiment can promote the tendency of CTD. If yes, the way it works is also worth exploring.

\section{Empirical Study}

\subsection{Subjects}

The subjects were 74 non-English majors from Huazhong Agriculture University. They were top students when enrolled as freshmen and randomly divided into experimental group and control group. Before a one year teaching practice a survey was conducted to ascertain the tendency of CTD of both groups. The statistics indicates that there is no significant difference CTD at .01 level ( $\mathrm{p}<.01)$. In table 1, group 1 refers to experimental class; group 2 stands for control group. 
Table 1. Descriptive data from preliminary questionnaire survey

\begin{tabular}{|c|c|c|c|c|}
\hline Variable & Group & Mean & Std. Deviation & Sig.(2-tailed) \\
\hline \multirow{3}{*}{ Truth-seeking } & 1 & 26.9756 & 7.16759 & .057 \\
\cline { 2 - 5 } & 2 & 30.1818 & 6.99310 & .057 \\
\hline \multirow{3}{*}{ Open-mindedness } & 1 & 28.6829 & 6.16619 & .710 \\
\cline { 2 - 5 } & 2 & 28.1212 & 6.74888 & .713 \\
\hline \multirow{3}{*}{ Analyticity } & 1 & 25.9512 & 3.94304 & .043 \\
\cline { 2 - 5 } & 2 & 23.9091 & 4.57823 & .047 \\
\hline \multirow{2}{*}{ Systematicity } & 1 & 28.4146 & 6.35994 & .149 \\
\cline { 2 - 5 } & 2 & 30.6364 & 6.69337 & .151 \\
\hline \multirow{2}{*}{ Self-confidence } & 1 & 29.0732 & 6.20641 & .253 \\
\cline { 2 - 5 } & 2 & 27.3333 & 6.74382 & .257 \\
\hline \multirow{2}{*}{ Inquisitiveness } & 1 & 25.3902 & 8.03081 & .540 \\
\cline { 2 - 5 } & 2 & 24.2424 & 7.87810 & .975 \\
\hline \multirow{2}{*}{ Maturity } & 1 & 27.9756 & 9.29109 & .975 \\
\cline { 2 - 5 } & 2 & 27.9091 & 8.89299 & .984 \\
\hline \multirow{2}{*}{ Overall score } & 1 & 192.4634 & 24.26633 & .985 \\
\cline { 2 - 5 } & 2 & 192.3333 & 32.77257 & \\
\hline
\end{tabular}

\subsection{Instruments}

The instrument in the study includes a questionnaire survey and a semi-structured interview. The questionnaire is CCTDI-CV (California Critical Thinking Disposition Inventory-Chinese Version) revised and tested by Peng Meici [16]. It has been widely accepted as an inventory with high validity and reliability.

\subsection{Procedure}

The research was initiated at the end of the first term. Both groups shared the same class hours. The difference lies in that the learning content for the experimental group is theme-based while the learning material for the control group is all from the assigned textbooks. In the learning model of the experimental group, learning material are based on a series of themes and these themes are correlated with each other. Students are not to be restricted within root learning of language forms. Instead they are driven to relate what they have learned to what they are learning and what they will learn. Therefore what they are involved in their learning experience includes relating, judging, analysizing, synthesizing and evaluating rather than isolated linguistic forms. After one-year teaching practice, the other questionnaire survey was conducted and data were collected and analysized afterwards.

\section{Results and Discussion}

\subsection{Results}

As indicated in table 2, a comparison between tendency of CTD before and after one-year teaching practice demonstrates that students in experimental group improved significantly in general tendency of CTD. As far as subscales concerned, they have advanced with significance in truth-seeking $(\mathrm{p}=.000)$ and systematicity $(\mathrm{p}=.000)$. The results reveals that students have acquired stronger disposition to critical thinking throughout one year content-based language learning. They get particularly stronger disposition in seeking the truth and knowledge. It is equally noteworthy that they exemplify greater ability in organizing and getting orderly focused after one academic year. 
Table 2. Report of paired-sample t-test of experimental group

\begin{tabular}{|c|c|c|c|c|}
\hline Variable & Mean & Std. Deviation & Std. Error Mean & Std. Error Mean \\
\hline \multirow{2}{*}{ Truth-seeking } & 26.9756 & 7.16759 & 1.11939 & \multirow{2}{*}{.000} \\
\hline & 33.6341 & 4.79456 & .74878 & \\
\hline \multirow[b]{2}{*}{ Open-mindedness } & 28.6829 & 6.16619 & .96300 & \multirow[b]{2}{*}{.784} \\
\hline & 28.4634 & 4.11155 & .64212 & \\
\hline \multirow{2}{*}{ Analyticity } & 25.9512 & 3.94304 & .61580 & \multirow{2}{*}{.978} \\
\hline & 25.9268 & 4.64968 & .72616 & \\
\hline \multirow{2}{*}{ Systematicity } & 28.4146 & 6.35994 & .99326 & \multirow{2}{*}{.000} \\
\hline & 32.4878 & 4.93012 & .76996 & \\
\hline \multirow{2}{*}{ Self-confidence } & 29.0732 & 6.20641 & .96928 & \multirow{2}{*}{.200} \\
\hline & 30.9268 & 6.40465 & 1.00024 & \\
\hline \multirow[b]{2}{*}{ Inquisitiveness } & 25.3902 & 8.03081 & 1.25420 & \multirow[b]{2}{*}{.564} \\
\hline & 26.1463 & 5.94374 & .92826 & \\
\hline \multirow{2}{*}{ Maturity } & 27.9756 & 9.29109 & 1.45102 & \multirow{2}{*}{.539} \\
\hline & 29.0244 & 5.56995 & .86988 & \\
\hline \multirow{2}{*}{ Overall score } & 192.4634 & 24.26633 & 3.78976 & \multirow{2}{*}{.000} \\
\hline & 206.6098 & 21.45912 & 3.35135 & \\
\hline
\end{tabular}

To evaluate the teaching effect in regular model in control group, a pair-sample t-test of control group was conducted. Data from table 3 indicates that students in control group do make some improvement in overall disposition to critical thinking. However it is not significant statistically. As to the scale of truth-seeking, it is the only subscale of CTD that control group demonstrates greater ability with statistical significance after experiment.

Table 3. Report of paired-sample t-test of control group

\begin{tabular}{|c|c|c|c|c|}
\hline Variable & Mean & Std. Deviation & Std. Error Mean & Std. Error Mean \\
\hline \multirow{2}{*}{ Truth-seeking } & 30.1818 & 6.99310 & 1.21734 & \multirow{2}{*}{.002} \\
\hline & 35.0606 & 5.89459 & 1.02612 & \\
\hline \multirow{2}{*}{ Open-mindedness } & 28.1212 & 6.74888 & 1.17483 & \multirow{2}{*}{642} \\
\hline & 28.8182 & 5.06492 & .88169 & \\
\hline \multirow{2}{*}{ Analyticity } & 23.9091 & 4.57823 & .79697 & \multirow{2}{*}{.607} \\
\hline & 24.4242 & 4.42317 & .76997 & \\
\hline \multirow{2}{*}{ Systematicity } & 30.6364 & 6.69337 & 1.16517 & \multirow{2}{*}{.422} \\
\hline & 31.9697 & 6.18711 & 1.07704 & \\
\hline \multirow{2}{*}{ Self-confidence } & 27.3333 & 6.74382 & 1.17395 & \multirow{2}{*}{.773} \\
\hline & 27.8485 & 5.58526 & .97227 & \\
\hline \multirow{2}{*}{ Inquisitiveness } & 24.2424 & 7.87810 & 1.37140 & \multirow{2}{*}{268} \\
\hline & 22.4848 & 5.53467 & .96346 & \\
\hline \multirow{2}{*}{ Maturity } & 27.9091 & 8.89299 & 1.54807 & \multirow{2}{*}{183} \\
\hline & 30.6061 & 6.61409 & 1.15137 & \\
\hline \multirow{2}{*}{ Overall score } & 192.3333 & 32.77257 & 5.70497 & \multirow{2}{*}{.254} \\
\hline & 201.2121 & 26.02614 & 4.53057 & \\
\hline
\end{tabular}

\subsection{Discussion}

From the data above, it can be discovered that students have acquired greater ability in CTD. This echoes with a consensus reached by a bunch of scholars who hold that the nurturing of CTD can be integrated with specific discipline or content learning [17]. Their marked improvement in truth-seeking and systematicity verify the advantages CBLL over the regular learning model. In the model of CBLL learning material is orderly organized and logically related. All the themes across the academic year are a systematic whole. This organization of learning content impress students with orderly organized thinking pattern. Therefore a growth in this subscale of CTD can be detected via the survey and verified by semi-structured interviews.

As to open-mindedness, it addresses being tolerant of divergent views and being sensitive to the possibility of one's own bias. However, as pointed out by Littlewood, Asian people accept the relationship based on power and authorities [18]. This tendency may prohibit students' development 
of critical thinking. From the interview, we found that they are more willing to obey what they are told and seldom challenge teachers' opinions.

\section{Conclusion}

The model of CBLL adopted in college English teaching combines language learning and content learning together. It is a model in which students can acquire a second language by analysizing, synthesizing, and evaluating learning material based on a series of correlated themes. The present study testifies the effective impact of CBLL on the subjects' CTD. Therefore, it is helpful to adopt CBLL in cultivating students' disposition toward critical thinking.

\section{Acknowledgments}

This research was financially supported by Project 2662015RW005 of the Fundamental Research Funds for the Central Universities.

\section{References}

[1] Vygotsky LS. Thought and Language [M]. Cambridge, M A the MIT Press, 1962.

[2] Zhu zhixian, Lin Chongde. Thinking Development Psychology [M]. Beijing: Beijing Normal University Publishing Group, 2002.

[3] Renner C E Enrich Learners' Language Production through Content-based Instruction [R] Modena, Italy. The National Conference on Linguae Nuova Didattica, 1996.

[4] American Philosophical Association. The Delphi report executive summary: Research findings and recommendation prepared for the committee on pre-college philosophy [R]. Retrieved from ERIC Doc. No. ED 315423, 1990.

[5] Giancarlo, C. A. \& P.A. Facione. A look across four years at the disposition toward critical thinking among undergraduate students [J]. The Journal of General Education, 50 (1), 2001.

[6] Cisneros, R.M. Assessment of critical thinking in pharmacy students [J]. American Journal of Pharmaceutical Education, 73 (4), 2009.

[7] Yi LIU, Ju-Ming ZHAO.The Investigation of Undergraduate Students' Critical Thinking Disposition-Taking a Local Comprehensive University as an example. Research in Higher Education of Engineering, 1, 2010, p.81-85.

[8] Yue MA. On the Critical Thinking Disposition of English Majors. Journal of Guangdong University of Foreign Studies, 22 (4), 2011, p. 92-95.

[9] Qiu-Fang WEN. The Development of Critical Thinking Disposition of Foreign Language Majors: A Longitudinal Study. Technology Enhanced Foreign Language Education, 167, 2016, p. 3-16.

[10] Krashen, S. The Input Hypothesis. Issues and Implications. Longman, 1985.

[11] Gass, S., \& Mackey, A. Input, Interaction, and Output in Second Language Acquisition. In B. VanPatten, \& J. Williams (Eds.), Theories in Second Language Acquisition. Mahwah/NJ: Erlbaum.2007, pp. 175-199.

[12]Facione, P.A. The disposition toward critical thinking [J]. Journal of General Education, 44(1) (1995), p.1-25.

[13]Lampert, N. Critical thinking dispositions as an outcome of undergraduate education [J]. The Journal of General Education, 56 (1), 2007. 
[14] Tufekci, et al. Critical thinking disposition of nursing students and influencing factors in Turkey [J]. Journal of Society for Development in New Net Environment in B \& H, 5 (4), 2011.

[15]Krasper, S., \& Terrell, T. The Natural Approach. Language Acquisition in the Classroom. Harlow: Pearson, 2000.

[16] Mei-Ci PENG, Guo-Cheng WANG, Ji-Le CHEN et al. Validity and Reliability of the Chinese Critical Thinking Disposition Inventory. Chinese Journal of Nursing, 39(9) (2004), p. 644-647.

[17]Pithers \& SodenCritical Thinking in Education: A Review [J]. Education Research, (2000) No.2, p. 237-249.

[18]Littlewood, W. Defining and Developing Autonomy in East Asian Context. System, Vol.20 (1999) No.1, p. 71-74. 